\title{
Au- and Ni-promoted Ce-Zr catalytic filter-SnO 2 integrated sensor for dual selective detection of ethanol and methane
}

\author{
F. Fateminia ${ }^{1}$, A. A. Khodadadi ${ }^{1}$, Y. Mortazavi ${ }^{1}$ \\ 1 School of Chemical Engineering, Colleges of Engineering, University of Tehran, Tehran, Iran. \\ Corresponding author's e-mail address: khodadad@ut.ac.ir
}

\begin{abstract}
Gold and nickel nanoparticles on the $\mathrm{Ce}_{0.8} \mathrm{Zr}_{0.2} \mathrm{O}_{2}$ mixed oxide are used as a catalytic filters for selective detection of ethanol and methane in presence of $\mathrm{CO}$. Thick film $\mathrm{SnO}_{2}$ gas sensor was covered with $\mathrm{Au} / \mathrm{Ce}-\mathrm{Zr}$ or $\mathrm{Ni} / \mathrm{Ce}-\mathrm{Zr}$ thick layers, to oxidize either $\mathrm{CO}$ or ethanol at different temperatures. A flow system was used to measure the sensor response to $300 \mathrm{ppm}$ carbon monoxide or ethanol and $5000 \mathrm{ppm}$ methane at $100-480^{\circ} \mathrm{C}$. Without using the filter, the $\mathrm{SnO}_{2}$ sensor shows comparable responses to carbon monoxide and methane and much higher ones to ethanol. The $\mathrm{Au} / \mathrm{Ce}-\mathrm{Zr}$ catalytic filter completely converts carbon monoxide and ethanol to the insensitive $\mathrm{CO}_{2}$ at 200 and $350^{\circ} \mathrm{C}$, respectively. The corresponding temperatures for $\mathrm{Ni} / \mathrm{Ce}-\mathrm{Zr}$ catalytic filter are 380 and $410^{\circ} \mathrm{C}$. No significant conversion of methane is observed at $100-480^{\circ} \mathrm{C}$ on none of the filters. The operating temperatures of the sensor covered with $\mathrm{Au} / \mathrm{Ce}-\mathrm{Zr}$ filter for selective detection of ethanol and methane are $200^{\circ} \mathrm{C}$ and higher than $350^{\circ} \mathrm{C}$, respectively. Applying Ni/Ce- $\mathrm{Zr}$ as a catalytic filter in the sensor-filter combination results in selectivity to methane at $400^{\circ} \mathrm{C}$. This way the integration of the sensor and $\mathrm{Au} / \mathrm{Ce}-\mathrm{Zr}$ catalytic filter with dual selectivity has a higher performance than Ni/Ce-Zr filter.
\end{abstract}

Key words: Tin, Gas sensor, Gold, Nickel, Ceria-Zirconia, Catalytic filter, Selectivity

\section{Introduction}

Ethanol sensors have widespread application in wine making, breathalysers, medical processes and food industries [1]. In addition, methane as one of the pollutant and the major constituent of natural gas for domestic and industrial applications is necessary to be detected [2] $\mathrm{SnO}_{2}$ n-type semiconductor is the most favorable sensing material with high sensitivity for fabrication of chemical gas sensors utilized for detection of various VOCs. One of the methods for the selectivity improvement of a sensor toward a target gas is applying a catalytic filter. Gold nanoparticles and metal oxide supported gold nanoparticles are very active to oxidize ethanol, carbon monoxide, and several VOCs to $\mathrm{CO}_{2}$ [3]. Moreover, $\mathrm{Ni}$ is one of the cheaper and highly active metal in most of the catalytic reactions and is better than noble metals economically [4]. On the other hand, the redox properties of $\mathrm{CeO}_{2}$ could be enhanced by introducing additional nickel $\mathrm{CeO}_{2}$ lattice via forming solid solutions.

Among the supports, ceria with high oxygen storage capacity (OSC) could be an appealing option and incorporation of zirconia in its lattice leads to higher redox property [5]. In this study, a dual selective sensor to ethanol and methane in the presence of $\mathrm{CO}$ as an interfering gas, using Au- and Ni-promoted Ce-Zr catalytic filter is introduced. Selectivity to methane by $\mathrm{Ni} / \mathrm{Ce}-$ $\mathrm{Zr}$ catalytic filter is another achievement of the sensor-filter system.

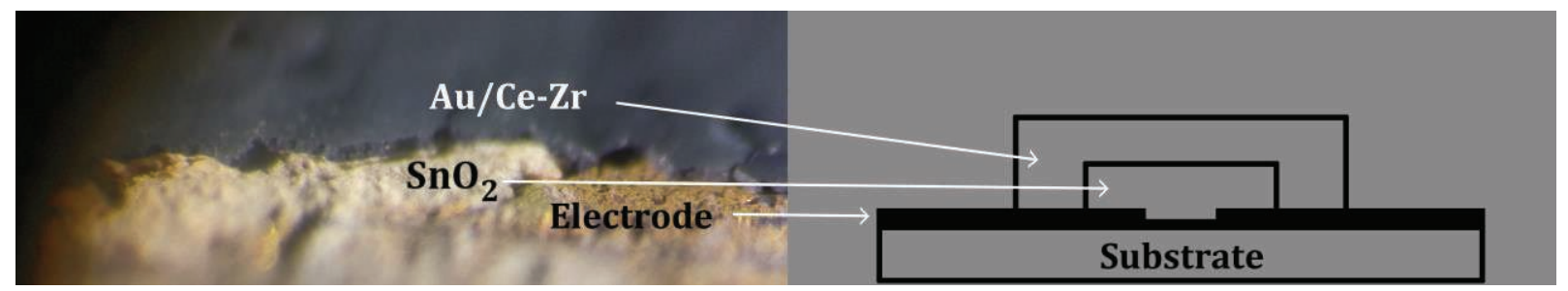

Fig.1. Optical microscope image of Au/Ce-Zr catalytic filter $70 \mu m$ thick on the surface of the thick-film $\mathrm{SnO}_{2}$ sensing material. 


\section{Experimental}

$\mathrm{Ce}_{0.8} \mathrm{Zr}_{0.2} \mathrm{O}_{2}$ mixed oxide was prepared via a coprecipitation method, and then promoted with gold nanoparticles (1.0 wt. \% Au/Ce-Zr) by a deposition-precipitation method. The ceriazirconia was promoted with nickel by a dry impregnation method to $5.0 \mathrm{wt}$ \% Ni/Ce-Zr. The $\mathrm{SnO}_{2}$ fine nanoparticles were synthesized by a precipitation method. A flow system was used to measure the sensor response to $300 \mathrm{ppm}$ carbon monoxide and ethanol and 5000 ppm methane at $100-480^{\circ} \mathrm{C}$ in absence or presence of the filters.

\section{Results, Discussions and conclusions}

Fig. 1 shows an optical microscope image of $\mathrm{Au} / \mathrm{Ce}-\mathrm{Zr}$ catalytic filter with the thickness of about $70 \mu \mathrm{m}$ on the surface of the thick-film $\mathrm{SnO}_{2}$ sensing material. Fig. $2 a$ shows that $\mathrm{Ni} / \mathrm{Ce}-\mathrm{Zr}$ catalytic filter completely oxidizes $\mathrm{CO}$ and ethanol at 350 and $410^{\circ} \mathrm{C}$, respectively. The corresponding temperatures for $\mathrm{Au} / \mathrm{Ce}-\mathrm{Zr}$ (see Fig. 2b) are 220 and $310^{\circ} \mathrm{C}$, respectively. Figure 3 illustrates the sensor responses to carbon monoxide, ethanol, and methane in the presence and absence of the catalytic filter located on $\mathrm{SnO}_{2}$ sensing layer. $\mathrm{SnO}_{2}$ shows comparable responses to carbon monoxide and methane and much higher ones to ethanol. Using Au/Ce-Zr catalytic filter, dual selectivities to methane and ethanol are observed at 350 and $200^{\circ} \mathrm{C}$, respectively. While only methane selectivity at $400^{\circ} \mathrm{C}$ is observed by applying $\mathrm{Ni} / \mathrm{Ce}-\mathrm{Zr}$. filter.
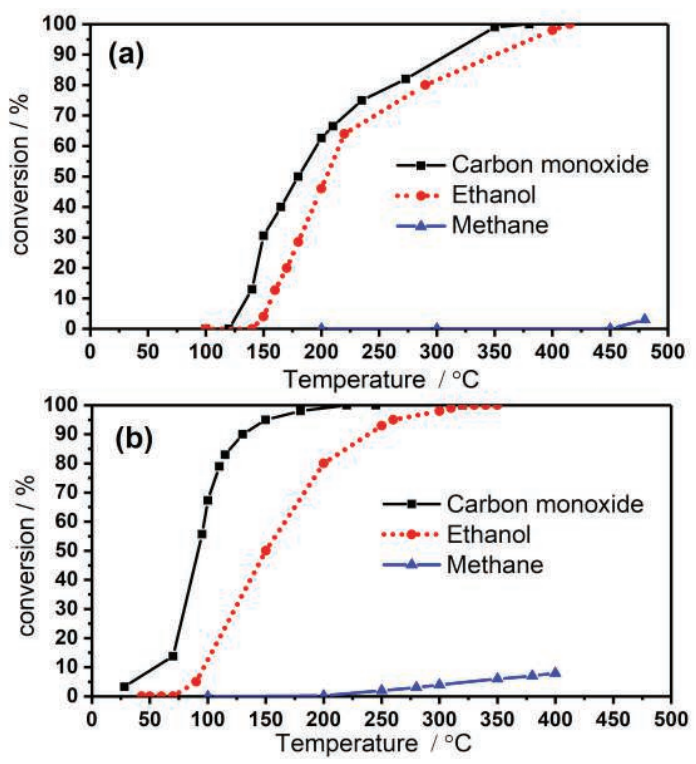

Fig. 2. The conversion-temperature curve of 300 ppm ethanol and carbon monoxide and $5000 \mathrm{ppm}$ methane in air on (a) $\mathrm{Ni} / \mathrm{Ce}-\mathrm{Zr}$ and (b) $\mathrm{Au} / \mathrm{Ce}-\mathrm{Zr}$ catalytic filters.
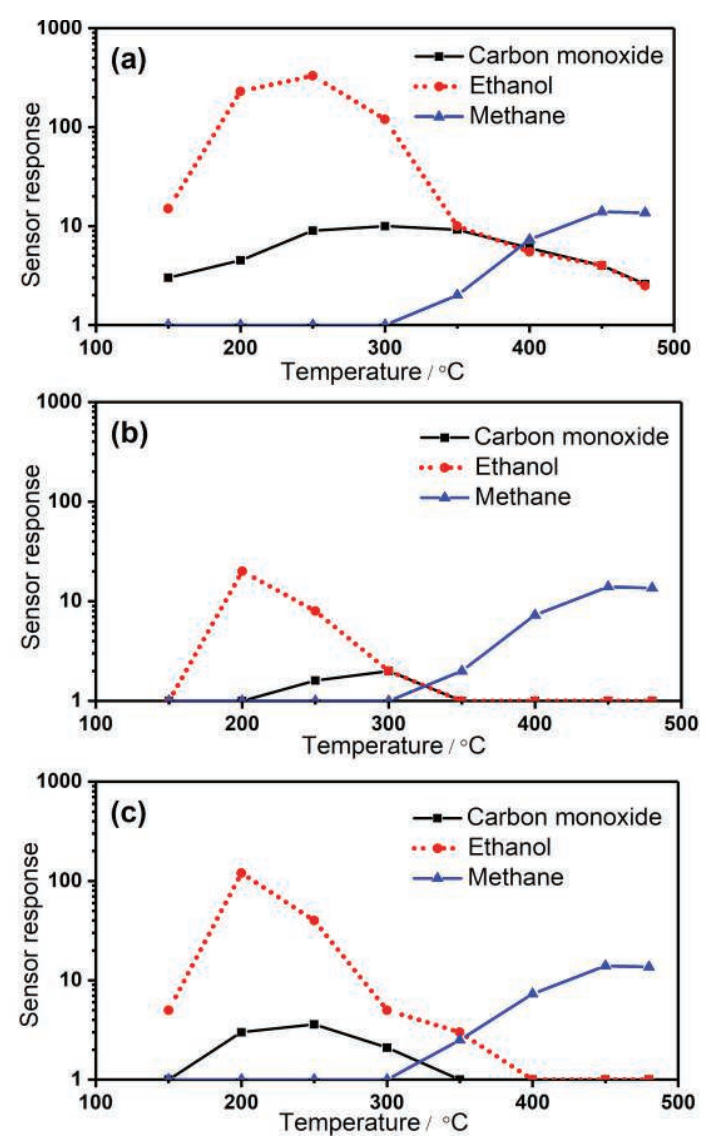

Fig. 3. Sensor responses to $300 \mathrm{ppm}$ ethanol, 300 ppm carbon monoxide and 5000 ppm methane in air (a) without the filter (b) with $\mathrm{Au} / \mathrm{Ce}-\mathrm{Zr}$ catalytic filter (c) with Ni/Ce-Zr catalytic filter.

\section{References}

[1] F. Pourfayaz, A. Khodadadi, Y. Mortazavi, S. Mohajerzadeh, $\mathrm{CeO} 2$ doped $\mathrm{SnO} 2$ sensor selective to ethanol in presence of CO, LPG and $\mathrm{CH} 4$, Sensors and Actuators B: Chemical, 108(2005) 1726; doi: 10.1016/j.snb.2004.12.107

[2] S. Basu, P. Basu, Nanocrystalline metal oxides for methane sensors: role of noble metals, Journal of Sensors, 2009(2009); doi: 10.1155/2009/861968

[3] J. Jońca, J. Harmel, L. Joanny, A. Ryzhikov, M.L. Kahn, P. Fau, et al., Au/MOx (M= Zn, Ti) nanocomposites as highly efficient catalytic filters for chemical gas sensing at room temperature and in humid atmosphere, Sensors and Actuators B: Chemical, 249(2017) 357-63; doi: 10.1016/j.snb.2017.04.061

[4] Sun, F.-m., C.-f. Yan, Z.-d. Wang, C.-q. Guo and S.I. Huang, $\mathrm{Ni} / \mathrm{Ce}-\mathrm{Zr}-\mathrm{O}$ catalyst for high $\mathrm{CO} 2$ conversion during reverse water gas shift reaction (RWGS), International Journal of Hydrogen Energy, 2015. 40(46): p. 15985-15993; doi: 10.1016/j.ijhydene.2015.10.004

[5] C. Pojanavaraphan, W. Nakaranuwattana, A. Luengnaruemitchai, E. Gulari, Effect of support composition and metal loading on $\mathrm{Au} / \mathrm{Ce}_{1-} \mathrm{ZrxO}_{2}$ catalysts for the oxidative steam reforming of methanol, Chemical Engineering Journal, 240(2014) 99-108; doi: 10.1016/j.cej.2013.11.062 